\title{
Is it Ethical to Offer ART in Transplant Patients?
}

\author{
Filipa AS*, Sara C, Filipa R, Cristina P, Marta L, Paula P \\ Department of Gynecology and Obstetrics, Nélio Mendonça Hospital, Portugal
}

Submission: October 03, 2017 ; Published: October 30, 2017

*Corresponding author: Filipa AS, Department of Gynaecology and Obstetrics, Nélio Mendonça Hospital, Avenida Luís de Camões 57, 9004-514, Funchal, Portugal, Tel: +351291705600; Email: filipaaasantos@gmail.com

\begin{abstract}
Numerous medical and surgical innovations have improved transplant recipient outcomes and this improved survival has led to an increased focus on their quality of life issues. This renewed focus includes controlling fertility and breeding. However, not all reproductive-age transplant recipients are able to conceive naturally. For this women in fertility is considered a threat to their quality of life. The decision to use Assisted Reproduction Techniques (ART) to help solid organ transplant female patients become pregnant raises unique medical and ethical concerns.
\end{abstract}

\section{Introduction}

Solid organ transplantation can prolong the life of individuals with end stage disease [1]. Numerous medical and surgical innovations have improved transplant recipient outcomes and this improved survival has led to an increased focus on their quality of life issues [1,2]. This renewed focus includes controlling fertility and breeding [3]. However, not all reproductive-age transplant recipients are able to conceive naturally. For this women, infertility is considered a threat to their quality of life [1,4]. An important question for this matter and that we should introduce at these point is: Is it lawful to offer these patients infertility treatments? And if so, how should the selection of these patients be made? Shall we use the same drug protocols and in the same dosages? Unfortunately, there is not a direct answer to these questions. We know that for women, both organ transplantation and IVF are independently associated with increased risks of preterm birth (PTB), low birth weight (LBW), small for gestational age babies (SGA) and perinatal mortality [4-6]. However, there is limited published data on pregnancy, delivery and the effect of ovarian stimulation on the graft, following ART, and so this is a controversial subject [1-7].

\section{Discussion}

Menstrual irregularity is common in women with chronic diseases. Nevertheless, normal menstrual and ovulatory function resumes the majority of them following successful organ transplantation, leaving many women with newly potential to conceive [1-3,8]. However, not all reproductiveage transplant recipients are able to conceive naturally. The decision to use Assisted Reproduction Techniques (ART) to help solid organ transplant female patients become pregnant raises unique medical and ethical concerns. A multidisciplinary team is required to address the complex medical, ethical and psychosocial issues involved in treating infertile transplant recipients [1-3,9-15]. Only a few case reports and small studies have previously been published regarding women with solid organ transplantation, which have delivered children after ART [3$6,16]$.

When reproductive specialists consider touse ART in transplant recipients they must first determine patient eligibility. Transplant recipients should be in good health and, ideally, graft function should be good to excellent, stable and rejection-free before attempting pregnancy [4]. In general, most transplant centres recommend a delay of pregnancy until 1 to 2 years following transplant $[4,5,17,18]$. Also, all comorbidities should be well controlled, the immunosuppressive regimen should be at the lowest dose and, if the underlying disease is genetically transmitted, it should be available a pre implantation genetic diagnosis (PGD) [1-5].

There are several ART techniques and the decision to perform one over other will depend on the fertility status of each couple. Usually, if the cause is an ovulation, the first technique to be performed is ovulation induction (OI), which is an easy process, normally achieved with the use of clomiphene citrate (CC), letrozole (LTZ) or low doses of gonadotropins $[19,20]$. When OI does not work, a step up in ART is to try intra-uterine insemination $[1,19,20]$. This technique is simple, hardly invasive and the higher risk to the transplanted patient is only related 
to the drugs used. When these two techniques are not enough or when the couples do not meet the requirements for their use (ex. if there is a tubal obstruction), the ART technique to use is in vitro fertilization (FIV) or intracytoplasmic sperm injection (ISCI) $[19,20]$.

During the cycle, the oocyte retrieval is this step where the risks are substantially larger in organ transplanted patients $[2,21]$. As these patients have multiple co-morbidities, general anaesthesia for oocyte retrieval has increased risk of complications. Therefore, at the beginning of the cycle a preanaesthetic appointment should be schedule in order to fully access the risk and prevent morbidity. 2 During de retrieval there is an actual risk of injuring the transplanted organ, when the organ is in the pelvic cavity, has it happens in renal transplanted patients. In these patients we also need to keep in mind other possible complications like thromboembolism (TE) due to the OHSS, oestrogens and surgical intervention $[14,21]$. Nonetheless, routine TE prophylaxis is not recommended [1,2]. After being approval and determined their eligibility, couples can begin the process on an Assisted Reproductive Unit, where they will start the usual ART study.

The goal of ART is to achieve a healthy child from an uncomplicated pregnancy, delivered at term, avoiding multiple gestations and ovarian hyper stimulation syndrome (OHSS), without detriment to maternal health [1,2]. Traditionally, in Europe, couples should choose to transfer one or two embryos, with the acquaintance that if two embryos are transferred there is a higher probability of a multiple pregnancy and all the risks inherent to it. For this matter, the trend nowadays is to do a single embryo transfer (SET) at the blastocyst stage [19]. This issue should be specially considered in solid organ transplanted patients who already have an increased risk of hypertension in pregnancy, pre-eclampsia, PTB and delivery SGA babies and do not need to overlap the increased risks of a multiple pregnancy [2-5]. For doctors, few data in the literature is available regarding the effect of ovarian stimulation or its complications on solid transplanted organs.

In this regard, it is not clear whether ovarian stimulation should be modified in any way [7]. Special care should be taken to avoid ovarian hyper stimulation and it is advisable to be conservative with the number of embryos transferred to avoid the risk of a high-order multiple pregnancy in an already highrisk medical condition [3,21]. Due to the lack of available data, the reproduction management of organ transplant recipients has been mostly extrapolated from renal transplantation evidencebased guidelines and experience, although care providers should always have in mind the differences between the transplanted organs [2].

\section{Conclusion}

A multidisciplinary approach is required to fully assess the advisability of proceeding ART in transplant recipients [1].
This approach has led to better candidate selection, treatment surveillance and improved outcomes, while decreasing complications [2]. This careful selection of patients will, hopefully, result in outcomes comparable to those in women who undergo solid organ transplantation and have a spontaneous conception [4]. A careful thought has to be made about the number of embryos to transfer and probably SET in solid organ transplanted patients probably should be the rule [21].

Nonetheless, to all that was said before, the couple should be made fully aware, through reliable information, of the potential risks associated with pregnancy and the use of ART in order to give appropriate informed consent before starting the techniques $[3,4]$. The couples should know that in nowadays there is little experience with the subject that literature is scarce but it is possible to conceive in safety using assisted reproductive technology, when certain requirements are fulfilled. Reporting the use of ART in these couples may help to create the necessary guidelines, forestall potential problems and allow couples to make an informed decision before undergoing treatment [7].

\section{References}

1. Nataki CD, Monrji S, Mark VS (2007) Fertility and Reproductive Disorders in Female Solid Organ Transplant Recipients. Semin Perinatol 31(6): 332-338.

2. Joao CDP, Mark VS (2014) Infertility and ART after transplantation. J bpobgyn 28: 1235-1250.

3. Case AM, Weissman A, Sermer M, Greenblatt EM (2000) Sucessful twin pregnanvy in a dual-transplant couple resulting from in-vitro fertilization and intracy to plasmatic sperm injection. Hum Reprod 15(3):626628.

4. Norrman E, Christina B, Ulla Britt W (2015) Pregnancy outcome and long-term follow-up after in vitro fertilization in women with renal transplantation. Human Reproduction 30(1): 205-213.

5. Jenifer KD, Roxane MR (2015) Pregnancy in women with solid-organ transplants: A review. Obstet Gynecol Surv 70(6): 408-418.

6. Kazem N, Yvonne B, Samir H, Johannes O, Stefan J, et al. (2011) Live birth after in vitro fertilization and single embryo transfer in a kidney transplant patient: a case report and review of the literature. J Assist Reprod Genet 28(4): 351-353.

7. Ulun U, Mesut A, Jozwiak EA, Bahceci M (2005) Successful pregnancy in a liver transplant recipiente following controlled ovarian hyperstimulation and intracytoplasmatic sperm injection. J Assist Reprod Genet 22(7-8): 311-313.

8. Ghazizadeh S, Lessan PM, Mohammd RK, Mahdavi MM, Mohammad RA, et al. (2007) Infertility among Kidney Transplant Recipients. Saudi J Kidney Dis Transplant 18(1): 79-82.

9. Sophia MT, Coscia LA, Potti S, Jason KB, Serban C, et al. (2011) National transplantation pregnancy registry (NTPR): in vitro fertilization outcomes in female transplant recipientes. AJOG 204(1): S322-S322.

10. Emidio VF, Margarida AP, Sandra S, Calejo L, Xavier P, et al. (2016) Assisted Reproductive Technology in Female Transplant Recipients: Experience of a Reproductive Medicine Unit and Literature Review. Acta Med Port 29(1):73-78.

11. Lockwood GM, Ledger WL, Barlow DH (1995) Sucessful pregnancy outcome in a renal transplant patient following in-vitro fertilization. Hum Reprod 10(6): 1528-1530. 
12. Furman B, Wiznitzer A, Hackmon R, Gohar J, Mazor M (1999) Multiple pregnancies in women after renal transplantation. Case report that rises a management dilemma. Eur J Obstet Gynecol Reprod Biol 84(1): 107-110.

13. Khalaf Y, Elkington N, Anderson H, Taylor A, Braude P (2000) Ovarian hyper stimulation syndrome and its effect on renal function in a renal transplant patient undergoing IVF treatment: Case report. Hum Reprod 15(6): 1275-1277.

14. Makoto T, Masafumi A, Naoki K, Takaaki T, Yoshihiko W, et al. (2003) Successful singleton pregnancy outcome resulting from in vitro fertilization after renal transplantation. Transplantation 75(7):1082-1083.

15. Fichez A, Labrousse C, Fromajoux C, Bordes A, Hadj S, et al. (2008) Successful pregnancy outcome after in vitro fertilization in a pancreas-kidney recipient. Fertil Steril 90(3): 849-849.

16. Pietrzak B, Mazanowska N, Kociszewska NB, Szymusik I, Grzechocińska B, et al. (2015) Successful Pregnancy Outcome after In Vitro Fertilization in a Kidney Graft Recipient: A Case Report and Literature Review. Ann Transplant 20: 338-334.

17. Christopher V, Al Chalabi T, Richardson PD, Muiesan P, Rela M. et al, (2006) Pregnancy outcome after liver transplantation: A single-centre experience of 71 pregnancies in 45 recipients. Liver Transpl 12(7): 1138-1143.

18. Dianne BM, Michelle AJ (2008) Pregnancy after Kidney Transplantation. Clin J Am Soc Nephrol 3(2):S117 S125.

19. Eshre (2008) Good Clinical Treatment in Assisted Reproduction an ESHRE position paper.

20. Carlos RI, Monteleone PAA, Serafini PC (2015) Human reproduction: current status. Rev Assoc Med Bras 61(6): 557-559.

21. Robinson L, Day C (2012) The renal transplant patient and IVF. In: Khaldoun S, Coomarasamy A (Ed.), Assisted reproduction techniques: challenges and management options. Wiley-Blackwell publication, New Delhi, India, pp. 87-90.

\section{Your next submission with Juniper Publishers} will reach you the below assets

- Quality Editorial service

- Swift Peer Review

- Reprints availability

- E-prints Service

- Manuscript Podcast for convenient understanding

- Global attainment for your research

- Manuscript accessibility in different formats

(Pdf, E-pub, Full Text, Audio)

- Unceasing customer service

Track the below URL for one-step submission https://juniperpublishers.com/online-submission.php 